\title{
The Role of Imaging Techniques in Diagnosing Pancreatic Cancer
}

\author{
LORENA SAS ${ }^{1}$, OANA TAISESCUㄹ, CITTO IULIAN TAISESCU2*, STEFAN-ALEXANDRU ARTENE4 , GINDROVEL DUMITRA5, \\ STEFANIA TUDORACHE ${ }^{6}$, ANICA DRICU ${ }^{4}$, TEODOR SAS $^{3}$ \\ 'University of Medicine and Pharmacy of Craiova,Department of Anatomy, 2 Petru Rares Str., 200349, Craiova, Romania \\ 2University of Medicine and Pharmacy of Craiova, Department of Physiology, 2 Petru Rares Str., 200349, Craiova, Romania \\ 3University of Medicine and Pharmacy of Craiova, Department of Radiology, 2 Petru Rares Str., 200349, Craiova, Romania \\ ${ }^{4}$ University of Medicine and Pharmacy of Craiova, Department of Biochemistry, 2 Petru Rares Str., 200349, Craiova, Romania \\ 5University of Medicine and Pharmacy of Craiova, Department of Pediatrics, 2 Petru Rares Str., 200349, Craiova, Romania \\ UUniversity of Medicine and Pharmacy of Craiova, Department of Obstetrics and Gynecology, 2 Petru Rares Str., 200349, Craiova, \\ Romania
}

\begin{abstract}
Imaging techniques play an essential role in the diagnosis, staging and establishing the treatment protocols in pancreatic cancer. Our proposed study explores and improves recent discoveries in the field of pancreatic cancer, especially relying on complex imaging techniques such as Computer Tomography (CT), Nuclear Magnetic Resonance (MR 3T), Ultrasonography (US) and Endoscopic Ultrasonography (EUS). In the case of pancreatic tumors, regardless of their origin, imaging exams also allow the evaluation of local and distant extension, with important prognostic and treatment ramifications. CT exams alongside RM and EUS offer a highly sensible and specific diagnosis of pancreatic tumors, with the added advantage of concomitant evaluation of adjacent parenchymatous abdominal organs.
\end{abstract}

\section{Keywords: Pancreatic cancer; Ultrasonography; Computer Tomography; Magnetic Resonance; Endoscopic Ultrasonography}

Imaging techniques have become more and more proeminent as first choice diagnostic options. Even if the "gold standard" for diagnosing pancreatic tumors is still based on an algorithm which involves ultrasound or CT guided biopsy followed by histopathological confirmation, evaluating external or internal parietal extension or lymph node invasion require other imaging techniques - US, CT, MR or positron-emission tomography (PET-CT) [1-4].

The fast face at which we improve our understanding of the carcinogenesis and the natural evolution of pancreatic cancer represents a good incentive to discover novel approches for diagnosing this affliction [5]. More so, the discovery of a large percentage of cancers where genetic factors play a major role, makes it possible to outline certain populations who are at risk and also makes it possible to improve the treatment strategies for these particular individuals [13]. Besides imagining techniques, other approaches have been taken into consideration in other forms of aggresive cancers where specific biomarkers are tested for their potential in diagnosis or treatment [6-9]. The presentstudy focuses on studying possible correlations between radiological characeristics of pancreatic tumors.

The aim of this study was to evaluate patients based on algorhitms involving US, CT, high performance MR and EUS, as well as studying certain possible correlations between radiological characteristics of pancreatic tumors.

\section{Experimental part}

\section{Materials and method}

The study was carried out as a prospectiv study at the Department of Radiology and Medical Imaging, Craiova Emergency County Hospital, the Imaging Compartment, Research Center in Gastroenterology and Hepatology and the Pathology and Histopathology and Immunohistochemistry Laboratories of the Morphopathology Department at the University of Medicine and Pharmacy of Craiova.

The study was performed on a group of 201 patients with the following pancreatic tumors: 170 adeno- carcinomas, 24 cystadenocarcinomas, 5 pancreatic metastasis and 2 neuroendocrine tumors (insulinomas).

CT examination was carried out using a SIEMENS SOMATOM unit with 20 spires. Imaging exploration was performed sequentially, with our without non-iodine based contrastagents administered orally or intravenously. Patient body scan was performed continously, with a low examination period, with concomitant data acquisiton, during a single apnoea period without any respiratory movement-generated artifacts. The orally administered contrast agent used was Gastrografin $(200 \mathrm{~mL}$ with 20 min before the examination and another $400 \mathrm{~mL}$ imediately before the examination, in order to observe the distension and opacifiation of the duodenum.

CT examination was initiated with a topogram on which the areas of interest were highlighted, followed by cross sections using $5 \mathrm{~mm}$ slices gapped by $5 \mathrm{~mm}$, and $3 \mathrm{~mm}$ slices gapped by $3 \mathrm{~mm}$ for small lesions, respectively.

For the postcontrast study, non-iodine based intravenous contrast agents were used-Ultravist 370 and Iopamiro 370, with overall low toxicity and good local and tissular tolerance. $\mathrm{A} 1 \mathrm{~mL} / \mathrm{kg}$ bodyweight bolus dose was administered, followed by the same type of sections and subsequent comparison between the resulting images.

Image acquisition was perfomed in the arterial, parenchymal and venous portal phases in order to differentiate bening and malignant pancreatic tumors. The venous portal and the parenchymal phases proved to be superior to the arterial phase in detecting malignanttumors, especially pancreatic adenocarcinomas. The arterial phase was useful for visualizing pancreatic blood vessels, while the portal phase proved to be more useful in detecting vascular invasion and liver metastatis. The images obtained using 3D, multiplanar in coronal and sagittal planes and volumetric reconstructions were stored on DVDs and printed on radiology film in certain cases.

MR was performed using a Philips Ingenia 3 Tesla system. The MR-based imaging techniques are: T1 FLASH weighted sequences (fast low angle shot) or 2DFSPGR 
(fast spoiled gradient recalled) with fat suppression; T2 HASTE weighted sequences (half fourier single shot turbo using echo) and T2 sequences with fat supression; i.v. contrast-enhanced 3D FSPGR MR angiography sequences during the arterial, venous and parenchymal phases were used in the case of tumors invading adjacent vascular structures.

The examination was performed with the help of a phased-array antena, with the patient lying on his back, with or without a paramagnetic i.v. constast agent. The advantage of using a phased-array antena is represented by an improved signal/noise ratio which translates into higher quality images. It is preferable for the patient to be fasting for at least $6 \mathrm{~h}$ before the examination, with the option of using glucagon to inhibit peristaltic movement. The constrast agent used was gadolinium-chelate in a 0.1 $\mathrm{mmol} / \mathrm{kg}$ bodyweight dose. The acquisitions were performed in cross, sagittal and coronal sections, with a thickness of 2-3 mm per slice.

Magnetic resonance cholangiopancreatography (MRCP) as a newly developed imaging technique was used to enhance RM. The method highlights the pancreatic and billiar ducts due to their liquid-rich content. Weighted T2 sequences were used in which fluids showed a hyperintense signal. The acquisition was made in a coronal plane for a better enhancement of the pancreatic and billiar ducts. The processing of the 3D images was done using a high-performing algorithm.

Trans-abdominal US exam. The trans-abdominal US exams were done using ALOKA SSD 5000 and HITACHI 8500 EUB US equipment. The examination was perfomed á jeun, with the patient in dorsal decubitus and/or leftlateral decubitus using the convex transducer with a 3.5-5 Mhz or a 2.5 Mhz frequence, respectively, for overweight patients, for obtaining axial, sagittal and oblique sections.

The epigastric window of approach, with transveral and oblique sections, was the most used for visualizing the longest pancreatic axis. In order to obtain a better window of exploration for vizualizing the pancreas, the patient was asked to take a deep breath and remain locked in inspiration (Valsalva maneuver) as much as possible. In order to visualize the pancreatic head, transveral and saggital sections were used, for the corporeal region transversal sections of the long axis of the lineal vein and sagittal sections of the aortic axis were used. The exploration of the caudal region of the pancreas was done using oblique sections through the subcostal area with the transducer aimed towards the splenic hillum and through the intercostal area.

Patients with tumors localized in the caudal region of pancreas were examined in right lateral decubitus, using the right kidney as a window of approach. Overweight patients or patients for which ultrasonography was made difficult by the presence of gas in the digestive tract were given $300-400 \mathrm{~mL}$ of plain water in order to create a ultrasonograpic window, with the examination being performed 5-10 min afterwards for a better vizualization of the head and body of the pancreas.

EUS was performed using an Olimpus UCT linear endoscopy system with a 5 and $10 \mathrm{Mhz}$ frequence transducer, linked to a ALOKA PROSOUND 5000 ultrasound unit and a HITACHI EUB 8500 ultrasound unit linked to Pentax linear endoscopic ultrasound system (EG 383 OUT). The examination was performed a jeun, using i.v. conscious sedation with midazolam (Dormicum) in most of the cases, with a small percetange of patients requiring i.v. propofol for sedation. Anti-spasticity agents such as butylscopolamine (Bucospan) were used for limiting duodenal motility.
A high-frequency US transducer placed at the end of an endoscope was used for the examination, which allowed the ultrasonographic transmural vizualization of the digestive tract walls as well as adjecent structures. The quality of the images was superior to those obtained using transabdominal US due to avoiding interposed structures such as fat or air.

\section{Results and discussions}

The patients' US examination recorded the location and the size of the tumor; the presence of elements characteristic for chronic pancreatitis (reduced volume; non homogenous, with an occasional nodular structure and with calcifications); the size of the Wirsung duct; the aspect of the gull bladder and the intrahepatic bile ducts; the presence of hepatic metastasis as well as lymph node metastasis; the absence or the presence of ascites.

The adenocarcinomas which could be visualized during the US exam presented as hypoechoic, poorly differentiated, irregularly shaped masses presenting a peripheral hypoechoic halo as a result of peritumoral sclerosis.

Regarding the location of the tumors, the results of the US exploration coincided with the CT scans, wih the majority of cancers being located in the head of the pancreas.

Additionally, the distension of the gull bladder was highlighted in $79.15 \%$ of the cases and the distension of the intrahepatic bile ducts in $76.78 \%$ of the cases, seen as transsonic images with a double duct aspect as well as a heavily enlarged main bile duct (fig. 1 and 2).

Small sized tumors localized in the head of the pancreas were difficult to detectusing US, requiring EUS and/or MRCP examination for vizualization. In the patient group, US did not visualize the pancreatic tumor in $29.36 \%$ of the cases, with overall sensibility for detectic pancreatic tumors being $67.66 \%$.

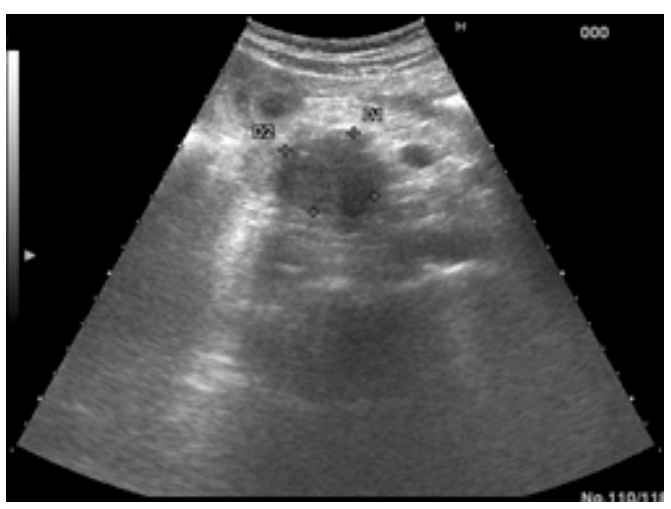

Fig. 1. Abdominal US- hypoechoic tumor, irregularly shaped, within the pancreatic head

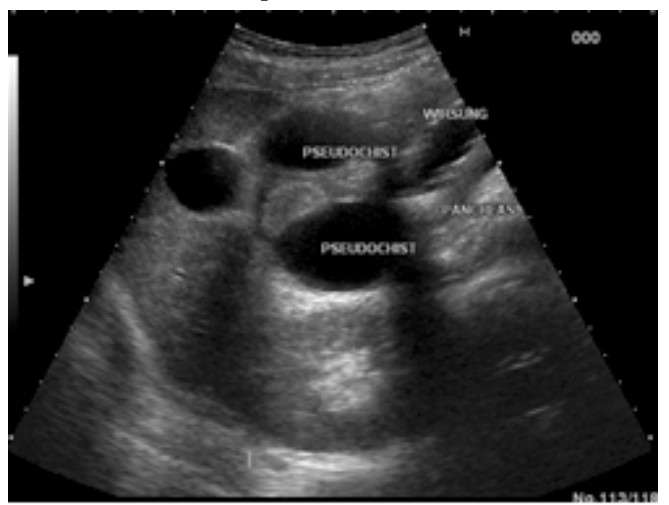

Fig. 2. Transabdominal US-tumor within the pancreatic head which produces

http://www.revistadechimie.ro 
The objectives of CT scanning were detecting: the size and interactions between the pancreatic tumor and adjecent structures; the presence and localization of metastasis; the presence of of locoregional and distant adenopathies.

CT examination highlighted the following aspects of the malignant tumors: the tumoral mass with a non homogenous structure and iodine uptake; tumoral necrosis with a hypodense aspect and fluid densities; cystic and tissular density structures indicative of malignant transformation; tumors of the pancreatic head were identified based on either complete blockage of the main bile duct determined by direct contact with the tumor or the double duct aspect presented as the distention of both the main bile duct and the pancreatic duct; the distention of the main bile duct and the intrahepatic bile ducts; the distention of the Wirsung duct coresponding to the body or the tail of the pancreas; the distention of the main bile duct; multiple images with low, iso/hypodense, low uptake densities sugestive of hepatic metastasis.

The optimum sequences were obtained during the arterial and portal phases. During the portal phase, the portal, superior mesenteric and peripancreatic veins present the maximum contrast, thus facilitating the discovery of the tumors and, in the same, the vizualization of the hypovascular hepatic metastasis which are more visible during this phase because of the high constrast of the hepatic parenchyma.

Using volumetric aquistions, arterial and superior abdominal 3D reconstructions were obtained which were useful in evaluating the direct contact between the neoplastic lesion and the peripancreatic vessels.

During the CT examination, TNM staging was also performed, identifying the criterias for unresectability as well as the disappearence of the pancreatic fat plane around the celiac trunk and the superior mesenteric artery.

Unlike abdominal US, the primary pancreatic tumor could not be visualized in only $10.5 \%$ of the cases with the accuracy of CT examination being $89.5 \%$ (figs. 3-5).

MRCP examination was useful in evaluating and characterizing the pancreatic adenocarcinomas as well as their staging.

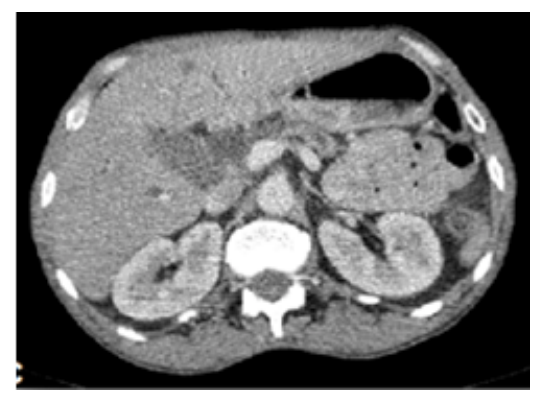

Fig. 3. Main bile duct with a $1.21 \mathrm{~cm}$ size

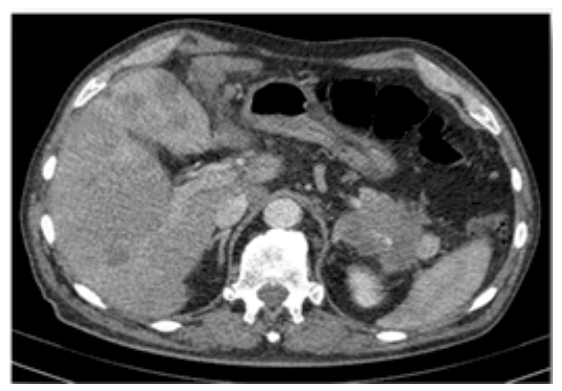

Fig. 4. Area with tissular densities, localized within the pancreatic tail, with invasion of the splenic vein and artery

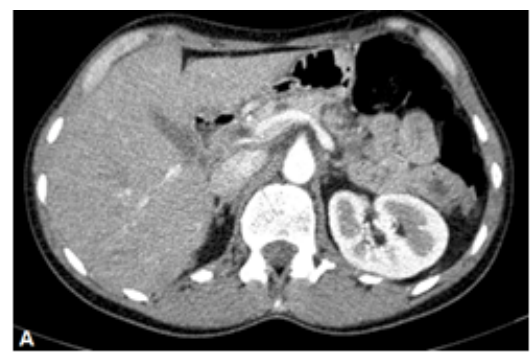

Fig. 5. CT exam with a contrast agent,

highlighting areas with cystic and tissue densities with the pancreatic body,

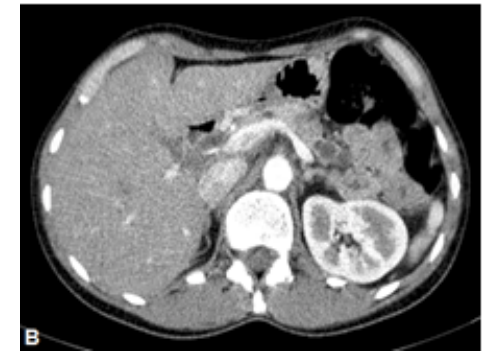

suspicious of malignant transformation

(A)-cystadenocarcinoma aspect; (B)-cysts within the pancreatic tail

The main objectives were: the presence of signal changes in the neoplastic lesions, such as hypointense signal during the T1 weighted sequences, iso/hyperintense signal during the T2 sequences due to necrosis or cystic degeneration; T1 hypointense signal after i.v. paramagnetic postcontrast; changes of the Wirsung duct.

Administering a paramagnetic contrast agent allowed us to visualize locoregional adenopathies, distant metastasis as well as vascular invasion when it was present, establising a correct preoperative assessement.

Adenopathies presented a hypointense signal in contrast to surrounding fat during T1 sequences without fat supression and a isointense signal during sequences with fat supression. During T2 sequences with fat supression adenopathies presented isointense signal and hyperintense signal during sequences with fat supression.

Hepatic metastasis were highlighted as having hypointense T1 signal, discretely hypointense T2 signal and hypointense postconstrast signal during weighted T1 sequences (fig. 6).

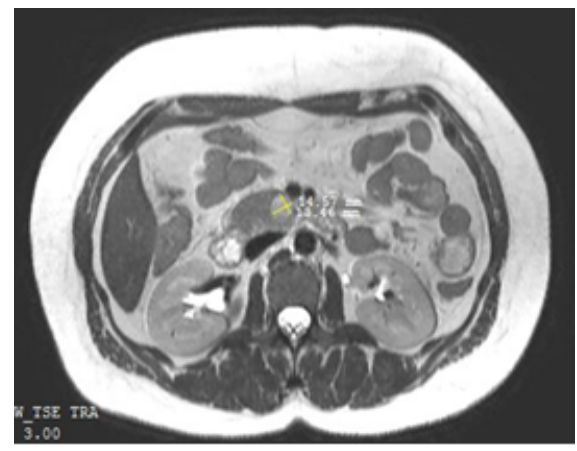

Fig. 6. RM 3T examination-insulinoma

MR 3T examination has pointed out the presence of a tissular mass in the uncinate process, with a minimal extension towards the pancreatic head, well delimited, with the disappeance of the anatomical space with the superior mesentheric vein; Wirsung duct with normal caliber and signal; the overall aspect suggests an insulinoma.

For 32 patients included in our study CT and MR examinations were not able to highlight the required characteristics for a complete diagnosis so additional information was obtained using EUS.

EUS was proved to be useful in staging pancreatic tumors and simultaneously enabled us to differentiate solid tumors from cystic, neuroendocrine or papillary tumors. 
The main advantage of the technique was the possibility to perform a ultrasound guided fine needle aspiration. For $4.9 \%$ of the patients EUS was not able to detect the main pancreatic tumor, these results being similar to those published in other studies whichdescribe EUS sensibility as being roughly $92 \%$.

The main goals of EUS exporations were: identifying the main tumor and accurately describing its' size; the presence of a Doppler signal in the tumor; visible tumor presence in the vascular lumen; blood vessels with an abnormal outline; the loss of the hyperechoic interface between the blood vessel and the parenchyma; colateral veins developed inside the tumor mass because of the obstruction of the main anatomical vascular trajectories; the presence of small sized mestastasis, localized within the left hepatic lobe, undetectable by abdominal US; EUS ductal and parenchymal criterias for chronic pancreatitis.

The most encountered EUS image was a hypoechoic, non homogenous tumor mass with a size between 15 and $50 \mathrm{~mm}$, with Doppler signal in the majority of cases (90\%) (figs. 7-9).

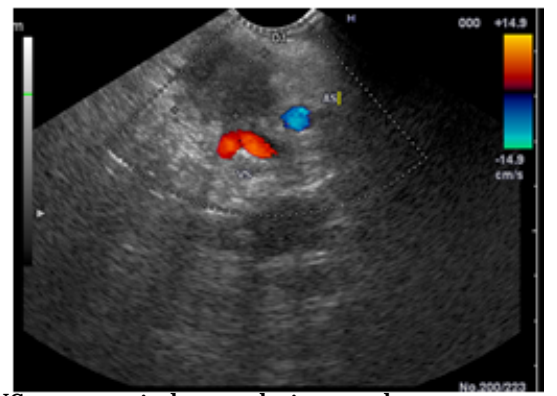

Fig. 7. EUS-pancreatic hypoechoic, non homogenous tumoral mass which comes in contact with the lineal artery and vein, without invading them

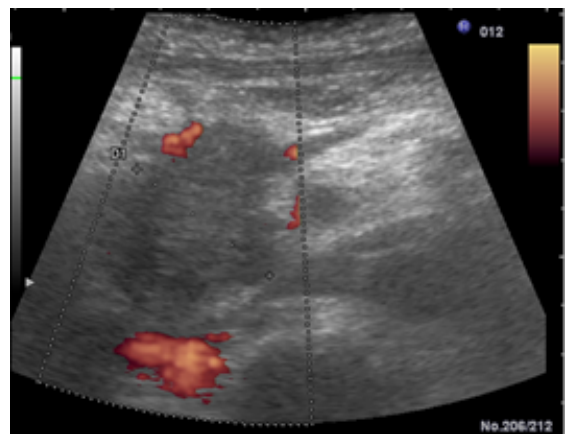

Fig. 8. Hypoechoic tumor mass, localized within the pancreatic head, with a size of $45 \mathrm{~mm}$; Doppler signal absense.

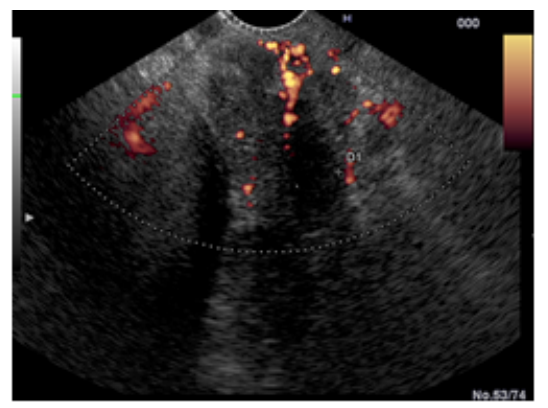

Fig. 9. EUS with power Doppler modeperipancreatic colateral circulation
Finally, EUS proved to be highly valuable in diagnosing and staging tumors of the pancreatic head, being superior to CT and MR examinations in most cases, especially for detecting small sized lesions.

The correlation between US studies and CT scans. The first set of statistical correlations was between the exploration systems used for detecting tumors and tumorlocalization. For calculating the degree of correlation between the two systems used for tumor evaluation (US and CT), we included the 170 patients evaluated using both methods, encompassing the overall tumor area. We maintained the same CT classification areas and the US segment classification, according to the criterias described under Materials and Method (table 1).

Segment analysis presented differences between US and CT examinations for describing tumor localisation.

For 10 of these patients, US examination indicated the presence of the tumor in a segment in the near vicinity of the of the area indicated by CT examination (fig. 10). Thus, 5 tumors which were initially described as being in the cephalic region of the pancreas, were placed in the adjacent area mentioned by the CT scan. Additionally, seven tumors which were initially placed inside the pancreatic body were described as being a part of the caudal region of the pancreas after CT examination (fig. 10).

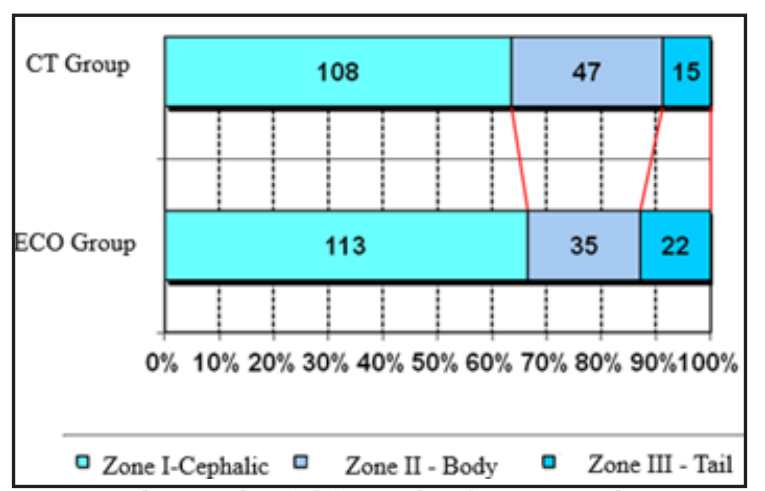

Fig. 10. The weight of different localizations within anatomic segments according to each investigation technique

Statistical analysis of the correlations between the two methods used for evaluating carcinomas was based on the $\chi^{2}$ correlation test. Using this algorithm, the evaluation techniques in our study proved to be highly efficient in locating tumors, represented by the $p$ value determined for each value obtained using the $\chi^{2}$ test (table 2 ).

In all cases, the relative error for locating the tumor was due to the large size or shape of tumors which created the impression of the neoplastic lesion originating in one area while extending in another. For this reason, we considered that the US-based diagnosis had a high degree of relative correlation, in concordance with with the diagnosis obtained from the CT scan. The correlations between the endoscopic and CT examinations. The global assessment of the size of the tumor has led to their induction into 3 sets of categories $(I=<2 \mathrm{~cm}, I I=2-4 \mathrm{~cm}, \| I=>4 \mathrm{~cm})$ following the measurements done using the two evaluation techniques (both EUS and CT scan).

The weight of the defining classes has justified the presence of a larger number of tumors diagnosed as having

\begin{tabular}{|l|c|c|c|}
\hline \multicolumn{1}{|c|}{ Group } & $\begin{array}{c}\text { Pancreatic } \\
\text { Segment }\end{array}$ & $\begin{array}{c}\text { US General } \\
\text { Group }\end{array}$ & $\begin{array}{c}\text { CT General } \\
\text { group }\end{array}$ \\
\hline Area I & head & 113 & 108 \\
\hline Area II & body & 35 & 47 \\
\hline Area III tail & 22 & 15 \\
\hline \multicolumn{2}{|r|}{ Total } & 170 & 170 \\
\hline
\end{tabular}

Table 1

PATIENT DISTRIBUTION ACCORDING TO SEGMENT LOCALIZATION AND ANATOMIC AREAS OF THE PANCREAS 


\begin{tabular}{|c|c|c|c|c|}
\hline & \multicolumn{3}{|c|}{ CT group } \\
\hline & & Area I & Area II & Area III \\
\hline \multirow{3}{*}{ 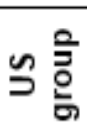 } & Area I & 108 & 5 & 0 \\
\hline & Area II & 0 & 47 & 5 \\
\hline & Area III & 0 & 7 & 15 \\
\hline \multirow{2}{*}{\multicolumn{2}{|c|}{$X^{2}$ test }} & DF & Value & $\mathbf{p}$ \\
\hline & & 4 & 177.125 & $<0.0001$ \\
\hline
\end{tabular}

Table 2

RESULTS OF THE CHI-SQUARED TEST FOR THE CORRELATION BETWEEN ANATOMIC AREAS AND THE TWO IMAGING TECHNIQUES between 2 and $4 \mathrm{~cm}$ using a CT scan compared to the lot examined using EUS, where the majority of tumors diagnosed had under two centimeters (table 3) (fig. 11).

The statistical analysis of the correlations between the two methods used in measuring the size of carcinomas was based on the $\chi^{2}$ correlation test.

Table 3

CT/EUS TUMOR SIZE

\begin{tabular}{|l|c|c|c|}
\hline Class & $\begin{array}{c}\text { Endosco } \\
\text { pic size }\end{array}$ & $\begin{array}{c}\text { EUS } \\
\text { group }\end{array}$ & CT group \\
\hline I & $<2 \mathrm{~cm}$ & 10 & 6 \\
\hline III & $2-4 \mathrm{~cm}$ & 14 & 15 \\
\hline III & $>4 \mathrm{~cm}$ & 8 & 11 \\
\hline
\end{tabular}

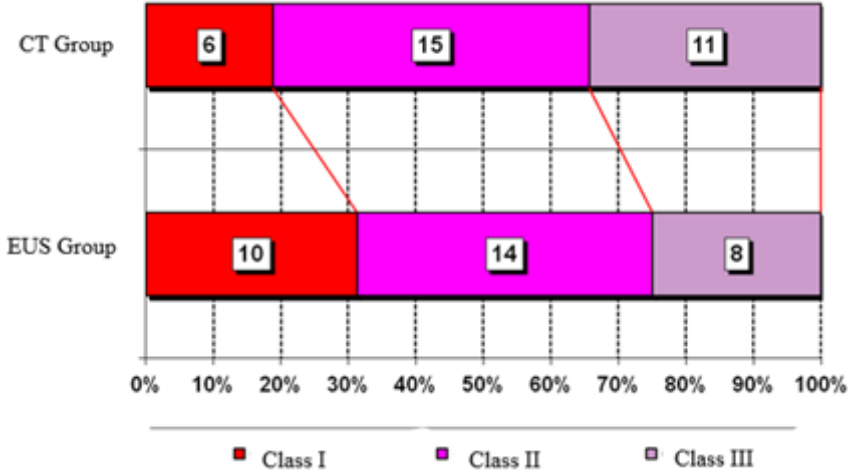

Fig. 11. Tumor size according to $\mathrm{CT} / \mathrm{EUS}$
In this situation, the correlation in terms of tumor size between the two evaluation techniques was statistically significant, based on the $p$ values determined from each result of the chi-squared test (table 4).

The comparative analysis of the tumor size using the two techniques was shown to be similar for 23 of the patients, representing $73 \%$ of the cases studied.

For the remaining 9 patients in our study, we recorded differences between the two exploration techniques.

For 8 of these patients, the difference resulted from underestimation of tumor size following CT examination in comparison to EUS, the latter proving to be more reliable in aproximating the tumor size (table 4). A single case was registered in which the tumor size was overestimated, mainly due to the tumor being an insulinoma which the CT scan could not detect while EUS managed to identify it.

Overall, in an overwhelming percentage of cases CT examination underestimated the size-based staging of the tumor in comparison to EUS, the main reason being that CT examination only took the tumoral surface into account whilst ignoring the size of the tumor in its entirety, size which proved to be notably larger, as we have seen.

This conclusion is sustained, furthermore, through the study of the statistical parameters obtained from the measurements performed by either CT or EUS. The statistical analysis using the t-test did not indicate any difference the tumor size for the two groups in terms of mean value or distribution based on size (table 5) ( fig. 12).

Thus, the interval bracketfor the results obtained through CT examination was larger than the one obtained using

\begin{tabular}{|c|c|c|c|c|c|}
\hline & \multicolumn{4}{|c|}{ CT } \\
\hline & & CLASS I & CLASS II & CLASS III & Total \\
\hline \multirow{4}{*}{$\stackrel{\boldsymbol{\omega}}{\vec{Z}}$} & CLASSI & 6 & 4 & 0 & 10 \\
\hline & CLASS II & 0 & 10 & 4 & 14 \\
\hline & CLASS III & 0 & 1 & 7 & 8 \\
\hline & Total & 6 & 15 & 11 & 32 \\
\hline \multirow{2}{*}{\multicolumn{2}{|c|}{$X^{2}$ test }} & & DF & Value & p \\
\hline & & & 4 & 57.026 & $<0.0001$ \\
\hline
\end{tabular}

Table 4

CHI-SQUARED TEST RESULTS BETWEEN THE TUMOR SIZES

\begin{tabular}{|c|c|c|c|}
\hline Statistic parameter & EUS & \multicolumn{2}{|c|}{ CT } \\
\hline SIZE-MAX & $5 \mathrm{~cm}$ & \multicolumn{2}{|c|}{$5.03 \mathrm{~cm}$} \\
\hline AVERAGE SIZE+STDEV & $5.65 \mathrm{~cm}$ & \multicolumn{2}{|c|}{$6.5 \mathrm{~cm}$} \\
\hline MEDIAN & $3.2 \mathrm{~cm}$ & \multicolumn{2}{|c|}{$3.7 \mathrm{~cm}$} \\
\hline AVERAGE SIZE & $3.54 \mathrm{~cm}$ & \multicolumn{2}{|c|}{$4 / 04 \mathrm{~cm}$} \\
\hline STANDARD SIZE-STDEV & $1.53 \mathrm{~cm}$ & \multicolumn{2}{|c|}{$1.58 \mathrm{~cm}$} \\
\hline SIZE-MIN & $1.5 \mathrm{~cm}$ & \multicolumn{2}{|c|}{$1.8 \mathrm{~cm}$} \\
\hline STDEV & 2.01 & \multicolumn{2}{|c|}{2.46} \\
\hline \multirow[t]{2}{*}{$t-\operatorname{tes} t$} & DF & Value & $\mathbf{p}$ \\
\hline & 170 & -0.826 & 0.409 \\
\hline
\end{tabular}




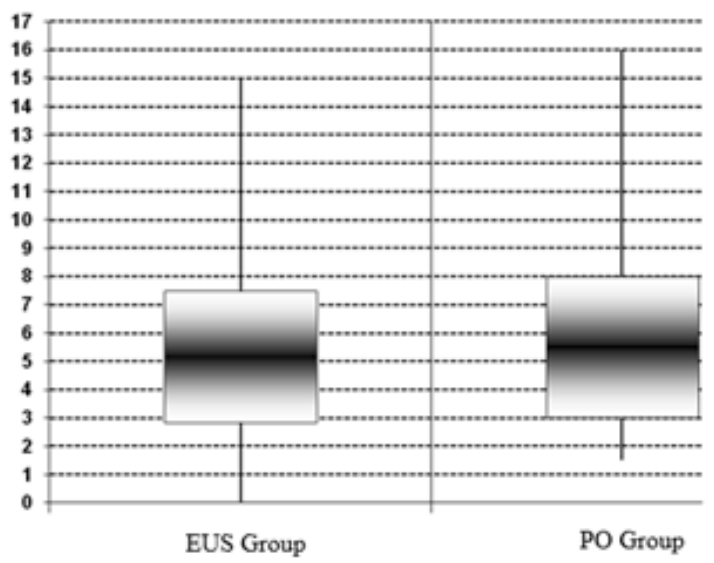

Fig. 12. Graphical representation of the statistical parameters

EUS. However, the interval in which the majority of results were situated, defined as the standard deviation for the mean value was larger for both groups and pushed towards the upper limit of the interval bracket due to the average size being, in both cases, larger than the mean value for the tumor size. It should be noted that tumors analyzed using CT scan presented an average tumor diameter larger than the ones examined with EUS.

Over $95 \%$ of solid malignant pancreatic tumors are represented by ductal adenocarcinomas [10]. In most of the cases, analyzing the tumors characteristics and distinguishing them from surrounding tissue has proven difficult despite the large number of imaging techniques being available [14-16], combinations of these techniques being necessary most of the time [11]. If a pancreatic mass is detected, a proper differential diagnosis is needed in order for the patient to receive proper treatment with the intention of improving the prognosis $[12,13]$.

At the moment, CT scan has proven to be the most reliable tool for diagnosing and staging pancreatic cancer [17]. MR is considered the mandatory imaging standard examination for the differential diagnosis of pancreatic masses $[11,19,20]$. The results of the microscopic examination are required for distinguishing between different types of pancreatic tumors [18, 24-26].

Studies by Prokop et al, Edlich et al and Haaga R.J et al with patients suspected as having pancreatic tumors have found changes in volume and density of the pancreas, the invasion of the peripancreatic fat, blood vessels and regional lymph nodes, as well as distant metastasis [1, 21, 22].

Bartalozzi and Catalano describe the RM characteristics of pancreatic tumors as hypo intense masses during the T1 weighted sequence [5, 23, 27, 28]. Additionally, the authors suggest that the pancreas is hyperintense in comparison to the liver during the T1 sequence, with the contrast between the tumor and normal parenchyma being stronger than the one between the pancreas and the liver $[23,29,30]$.

More so, the MR aspect of pancreatic adenocarcinomas in our study was represented by changes such as hypointense signal during the T1 sequence, iso/ hyperintense signal during the $\mathrm{T} 2$ due to the presence of necrosis and cystic degeneration and hypointense signal after the paramagnetic agent during the T1 sequence [24, $31,32,33]$. In addition, the examination using the contrast agent allowed us to formulate a correct preoperative assessement by visualizing vascular invasion, adenopathies or distant metastasis [11].

In order to describe focal pancreatic lesions, we used $b$ values of $0 \mathrm{~s} / \mathrm{mm}^{2}, 20 \mathrm{~s} / \mathrm{mm}^{2}, 500 \mathrm{~s} / \mathrm{mm}^{2}$ and $100 \mathrm{~s} / \mathrm{mm}^{2}$, resulting in a mean $A D C$ value for pancreatic adenocarcinoma [34-36] of $1.02 \pm 0,17 \times 10^{-3} \mathrm{~mm}^{2} / \mathrm{s}$, significantly higher than the one coresponding to acute pancreatitis which was $0.81 \pm 0.19 \times 10-3 \mathrm{~mm}^{2}$.

The results we obtained suggest that it's possible to differentiate between a pancreatic adenocarcinoma or an acute pancreatitis lesion and a chronic phase pancreatic mass $[37,38]$ by using large $b$ values during MR DWI sequences. This has been confirmed by other authors, as well [24].

\section{Conclusions}

Pancreatic cancer is a devastating disease, with an abysmal prognosis and an importantmortality and morbidity factor, which an increased incidence, according to our study. The analysis of the localization of the primary tumor seems to indicate that cancers of the pancreatic head are predominant, followed by body and tail in this particular order.

If the US represents the screening exam used for evaluating pancreatic pathology, useful for guiding tow ards a diagnostic, latest generation imaging techniques allow us to accurately describe the malignant lesion as well as the status of its progression.

CT plays a major role in exploring the hepatic-billiarypancreatic regions, with multislice spiral CT being a mainstay for describing pancreatic tumors. This technology allows the scanning of the whole abdomen within one cycle of voluntary apnea with concomitant analysis of the pancreas and secondary lesions, including pancreatic metastasis.

As for pancreatic tumors, regardless of origin, the imaging examination allows us to accurrately asses the loco-regional and distant extension of the tumor with great prognostic implications and concordant therapeutic decisions.

CT examination correlated with MR and EUS represent a higly specific and sensible option for detecting pancreatic cancer, with the added advantage of being able to simultaneously explore other parenchimatous organs of the abdomen.

\section{References}

1.HAAGA, J ,R, GILKESON, R.C. CT and MR Imaging of the whole body Vol2. London: Mosby, 2005.

2.DELBEKE, D., MARTIN, W.H. PET and PET/CT for pancreatic malignancies. Surg Oncol Clin N Am 2010; 19: 235-254.

3.GURAU, G., DINU, A.C., EARAR, K., VOICU, D.C, BOTEZATU, D. Rev. Chim. (Bucharest), 67, no. 3, 2016

4.BERBECE, S.I., CONDRATOVICI PLESEA, A., PAVEL, L.L., GRIGORE, A.C., Rev. Chim. (Bucharest), 68, no. 5, 2017, p. 1075-1076

5.CATALANO, C, PAVONE, P., LAGHI, A. et al.. Eur Radiol 1998; 8: 428434

6.SERBAN, F., ARTENE, S.A., GEORGESCU, A.M. Onco T. Ther 2015; 8: 3767-3774.

7.ALEXANDRU, O., PURCARU, S.O., TATARANU, L.G. et al. Int J Mol Sci 2018; 19.

8.WOOD, L.D., KLIMSTRA, D.S. Semin Diagn Pathol 2014; 31: $491-497$. 9.J ECAN, C.R., NICOLAU, A., FLORESCU, I.P., ARDELEANU, V., BERBECE, S., Mat.Plast., 54, no. 1, 2017, p. 88-90

10.AL-HAWARY, M.M., KAZA, R.K., AZAR, S.F. et al. Mimics of pancreatic ductal adenocarcinoma. Cancer Imaging 2013; 13: 342-349.

11.MEGIBOW, A.J., ZHOU, X.H., ROTTERDAM, H. et al. Radiology 1995; 195: 327-332.

12.TAISESCU, C.I., ILIESCU, G., TAISESCU, 0. et al.. Farmacia, 2015; 63 (3): $465-469$

13.CAPELLA, C., ALBARELLO, L., CAPELLI, P. et al. Dig Liver Dis 2011; 43 Suppl 4: S282-292. 
14. BERCEANU, C., PAITICI, S., BERCEANU, S., BRATILA, E., OFITERU, A.M., MEHEDINTU, C., BERBECE, S.I., NAVOLAN, D., OBLEAGA, C.V., BALSEANU, A.T., Rev. Chim. (Bucharest), 69, no. 8, 2018, p. 2245-2250 15. DINU, A.C., BRUJBU, I., CERGHIZAN, D., BULIMAR, V., MACOVEI, L.A., BOTEZATU, D. Rev. Chim. (Bucharest), 67, no. 6, 2016 16. ARDELEANU, V., BERBECE, S.I., FLORESCU, I.P., JECAN, C.R., Mat. Plast., 54, no. 1, 2017, p. 37-40

17.CHO, H.W., HOI J.Y., KIM M.J. et al. Korean J Radiol 2011; 12: 731739.

18.MARINELLI, T., FILIPPONE A., TAVANO F. et al. A tumour score with multidetector spiral CT for venous infiltration in pancreatic cancer: influence on borderline resectable. Radiol Med 2014; 119: 334-342.

19.FILIP, I.C., BERBECE, S., RADUCU, L., FLORESCU, I.P., ARDELEANU, V., JECAN, C.R., Mat. Plast., 54, no. 3, 2017, p. 414-417

20.TITIUCA, C., DINU, A.C., ALEXA, I.A., PRUNA, R., LUCA, M.C., DOROBAT, C., VATA, A., LUPOAE, M. Rev. Chim. (Bucharest), 67, no. 5, 2016

21.ENDLICH. R.F., FARINHOLT, H.M., WINTERS K.L. et al. J Long Term Eff Med Implants 2005; 15: 185-196.

22.PROKOP, M., SCHAEFER-PROKOP, C., GALANSKI, M. Spiral CT angiography of the abdomen. Abdom Imaging 1997; 22: 143-153.

23.BARTOLOZZI, C., LENCIONI, R., DONATI, F., CIONI, D. Abdominal MR: liver and pancreas. Eur Radiol 1999; 9: 1496-1512.

24. HOORENS, A., PRENZEL, K., LEMOINE, N.R., KLOPPEL, G. J Pathol 1998; 185: 53-60.

25.FATTAHI, R., BALCI, N.C., PERMAN W.H. et al.J Magn Reson Imaging 2009; 29: 350-356.
26.FUSARU, A.M., PISOSCHI, C.G., BOLD, A., TAISESCU, C.I. et al. Rom J Morphol Embryol 2012, 53(4):903-909

27.BERCEANU, C., CIUREA, E.L., CIRSTOIU, M.M., BERCEANU, S., OFITERU, A.M., MEHEDINTU, C., BERBECE, S.I., CIORTEA, R., STEPAN, A.E., BALSEANU, A.T., Rev. Chim. (Bucharest), 69, no. 9, 2018, p. 2396-2401

28.MACOVEI, L.A., CRISTESCU, V., DEBITA, M., DINU, A.C. Rev. Chim. (Bucharest), 68, no. 10, 2017, p. 2440

29.SCHORTGEN, F., GIROU, E., DEYE, N., BROCHARD L.; Cryco Study Group. Intensive Care Med. 2010 Oct;36(10):1724-34.

30.CHU, L.C., GOGGINS M.G., FISHMAN E.K. Cancer J. 2017 Nov/ Dec;23(6):333-342.

31.ISHIGUCHI, T., OTA, T., NAGANAWA, S., FUKATSU, H., ITOH, S., ISHIGACHI, T. Hepatogastroenterology. 2001 J ul-Aug;48(40):923-7

32.PETRESCU, I.O., BICIUSCA, V., TAISESCU, C.I. et al. Rom J Morphol Embryol 2016, 57(2 Suppl):759-765.

33.RAFTU, G., DEBITA, M., DINU, A.C., PANGAL, A.,HODOROG, D., CUCIUREANU, D.I. Rev. Chim. (Bucharest), 70, no. 1, 2019, p. 228

34.DELBEKE, D., PINSON, C.W. J Hepatobiliary Pancreat Surg. 2004;11(1):4-10.

35.DAIANU, O., GEORGESCU, A.M., CIUREA, M.E. et al. Int J Clin Exp Med 2016;9(8):15249-15261

36.BERBECE, S., ILIESCU, D., ARDELEANU, V., NICOLAU, A., JECAN, C.R. Rev. Chim. (Bucharest), 68, no. 7, 2017, p. 1438-1441

37.IRIE H., HONDA H., KANEHO, K., KUROIWA, T., YOSHIMITSU, K., MASUDA K. Abdom Imaging. 1997 J ul-Aug;22(4):429-33. 38.BALCI, N.C., SEMELKA R.C. EurJ Radiol. 2001 May;38(2):105-12.

Manuscript received: 14.12 .2018 